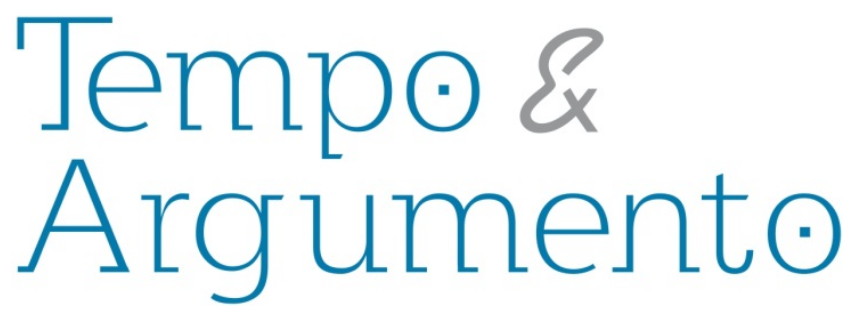

\title{
A Anistia Internacional e o Brasil: o princípio da não-violência e a defesa de presos políticos
}

\begin{abstract}
Resumo
Durante o regime militar brasileiro, em meio à institucionalizada prática da tortura, a organização de direitos humanos, Anistia Internacional, trabalhou na defesa de presos políticos e na divulgação de denúncias de violações de direitos humanos entre a comunidade internacional. Como parte de um projeto de pesquisa mais amplo, cujo objetivo é investigar a atuação da Anistia Internacional no Brasil, o presente artigo pretende mostrar como a organização se posicionou em relação a aos presos políticos que pertenceram a organizações armadas, na medida em que a Anistia tinha como um de seus princípios a não-violência. Para tal, será feita uma análise da atuação da Anistia Internacional com base no conceito de compaixão de Hannah Arendt. $\mathrm{O}$ artigo mostra que a Anistia Internacional, apesar de condenar a violência como forma de luta política, atuou com solidariedade em relação à defesa de presos políticos que pertenceram a organizações armadas tanto na Alemanha, como no Brasil.
\end{abstract}

Palavras-chave: Anistia internacional; Regime militar brasileiro; Direitos humanos; Compaixão.

\section{Renata Meirelles}

Doutoranda em História Social pela Universidade de São Paulo.

Trabalhou como pesquisadora do Arquivo do Estado de São Paulo no projeto "Arquivos da repressão e da resistência: mapeamento e análise dos fundos DEOPS/SP e DEIP/SP". Pesquisadora do Grupo de pesquisa International State Crime Initiative (ISCI), King's College

London. Atualmente conduz pesquisa de doutorado intitulada

"Acendei as Velas: a Anistia Internacional e o Brasil (1961-1982)", sob o financiamento da FAPESP. renatameirelles@usp.br

\section{Para citar este artigo:}

MEIRELLES, Renata. A Anistia Internacional e o Brasil: o princípio da não-violência e a defesa de presos políticos. Revista Tempo e Argumento, Florianópolis, v. 6, n.11, p. 327-354, jan./abr. 2014.

DOI: $10.5965 / 2175180306112014327$

http://dx.doi.org/10.5965/2175180306112014327 


\title{
Amnesty International and Brazil: The principle of nonviolence and the defense of political prisoners
}

\begin{abstract}
During the Brazilian military regime, with the institutionalization of torture, a human rights organization - Amnesty International - worked on the behalf of political prisoners and for publishing human rights abuses charges among the international community. As part of a larger research project, which intends to investigate the work of Amnesty International in Brazil, this article aims to show how the organization dealt with the cases of political prisoners who belonged to armed organizations, as Amnesty had nonviolence as one of its principles. In order to do so, I shall analyze Amnesty International's work using Hannah Arendt's concept of compassion. This article shows that although Amnesty International condemned the use of violence as a form of political struggle, it acted with solidarity with the defense of political prisoners who belonged to armed organizations both in Germany and Brazil.
\end{abstract}

Keywords: Amnesty international; Brazilian military regime; Human rights; Compassion. 


\section{A Anistia Internacional e os presos políticos brasileiros}

Em fins dos anos 1960, durante os governos de Artur da Costa e Silva e de Emílio Garrastazu Médici, concomitantemente à já institucionalizada utilização da tortura como forma de investigação de crimes políticos e intimidação dos movimentos de oposição ao regime militar brasileiro, ${ }^{1}$ a organização de direitos humanos Anistia Internacional trabalhou na defesa de presos políticos brasileiros e para divulgar, entre a comunidade internacional, denúncias de violações de direitos humanos ocorridas no Brasil.

Para a libertação de presos políticos, a Anistia Internacional tinha como principal estratégia a escrita de cartas tanto para os presos quanto para as autoridades que os encarceravam. Assim, a organização buscava transmitir a mensagem de que aqueles indivíduos não haviam sido esquecidos; de que alguém, em alguma parte do mundo, manifestava preocupação com a sua integridade. Com isso, esperava-se que os prisioneiros em questão fossem libertados ou que recebessem melhor tratamento.

O princípio de não-violência constituiu uma das orientações da Anistia Internacional, o que em tese poderia significar um impedimento para que a organização agisse com solidariedade em relação a presos políticos brasileiros, na medida que muitos pertenceram a organizações armadas. O presente artigo pretende identificar de que forma a Anistia Internacional lidou com o caso de presos políticos que recorreram à violência como forma de luta política. Conforme será mostrado ao longo do texto, o princípio da não-violência integrava um conjunto mais amplo de valores da Anistia Internacional, como a compaixão, solidariedade e amor ao próximo. Pretende-se entender como esses sentimentos foram mobilizados pela organização seguindo a apreciação do conceito de compaixão proposto por Hannah Arendt.

A Anistia Internacional se notabilizou por campanhas abrangentes, de alcance mundial e de defesa de direitos humanos, como a de combate a tortura, que ocorreu durante os anos 1970, e pela produção de relatórios anuais sobre a observância dos direitos humanos em diferentes países. Com a publicação de seus relatórios, os

\footnotetext{
${ }^{1}$ A institucionalização do aparato de repressão se deu por meio da implantação da Operação Bandeirantes (OBAN), em 1969, e da subsequente instalação dos DOI-CODI - Destacamento de Operações de Informações - Centro de Operações de Defesa Interna (DOI-CODI), órgãos subordinados ao Exército.
} 
integrantes da Anistia buscavam divulgar seu conteúdo para a imprensa como forma de pressionar aqueles governos que violavam os direitos humanos.

Para o caso do Brasil, durante o regime militar, uma das estratégias da organização consistiu em pressionar o governo brasileiro por meio do envio de cartas a diversas instâncias - autoridades federais, estaduais, municipais, Justiça Militar -, com o intuito de obter informações a respeito de indivíduos encarcerados. Assim, no período de junho de 1972 a abril de 1973, de acordo com a documentação da Divisão de Segurança e Informações do Ministério da Justiça, O SNI/AC recebeu cerca de 2.800 cartas de integrantes da Anistia, sendo a maioria delas provenientes da França, Holanda, Suécia e República Federal da Alemanha. ${ }^{2}$

A Anistia Internacional era bem conhecida pelos serviços de informação do governo Médici. É o que mostram os documentos da Divisão de Segurança e Informações do Ministério da Justiça:

1) A Amnesty International - Al - é uma organização privada com o objetivo declarado de ajudar prisioneiros condenados por motivos de suas convicções políticas ou religiosas, sem haver cometido atos de violência.

a) Origens: Em janeiro de 1961 o advogado londrino PETER BENENSON propôs, através de um artigo publicado, organizar uma campanha de anistia em favor dos "prisioneiros esquecidos". A proposta teve boa receptividade e a 28 de maio de 1961 foi fundada por PETER BENENSON, em Londres, a AI.

2) Atuação da Al com relação ao Brasil

A Al, através de suas vinculações com a Frente Brasileira de Informações (FBI), tem dirigido uma das mais acirradas campanhas difamatórias contra o Brasil. Sua atuação faz-se sentir de maneira tanto sistemática quanto eventual.

a) Atuação sistemática: através de cartas de apelo, de protesto e de consulta a respeito de subversivos. Esta correspondência tem sido submetida a Ministros de Estado, Auditores e Promotores da Justiça Militar, Autoridades Federais, Estaduais, Municipais e Eclesiásticas. A própria presidência da República tem sido destinatária deste tipo de correspondência.

No período de junho /72 a abril/73 o SNI/AC recebeu cerca de 2.800 cartas. A maioria delas provém da França, Holanda, Suécia e República

\footnotetext{
${ }^{2}$ Informe da Divisão de Segurança e Informações do Ministério da Justiça. 19 de Julho de 1973. BR.AN, RIO.TT.O.MCP.AVU.250. Arquivo Nacional/ RJ.
} 
Federal da Alemanha. Do exame dessa correspondência denota-se a má fé. ${ }^{3}$

É interessante observar que, ao mesmo tempo em que os órgãos de repressão do regime militar conheciam a Anistia Internacional, suas origens, formas de atuação e estratégias, a apreciação política que tinham sobre a organização não poderia ser mais fantasiosa, na medida em que a associaram ao "Movimento Comunista Internacional." Para o Serviço de Informações do Ministério da Justiça, a Anistia constituía um veículo de difusão de uma campanha difamatória contra o Brasil no exterior e agiria em conjunto com a Frente Brasileira de Informações (FBI), ${ }^{4}$ colaborando com o que chamavam "Movimento Comunista Internacional". ${ }^{5}$ Todavia, conforme será mostrado ao longo desse texto, a Anistia esteve bem distante da apreciação que os órgãos de repressão brasileiros tinham a seu respeito.

A Anistia Internacional, conforme indica o informe da Divisão de Segurança e Informações do Ministério da Justiça, de fato, foi fundada em 1961, pelo advogado britânico Peter Benenson, em Londres. A organização surgiu como desdobramento da campanha Amnesty, que tinha a finalidade de lutar pela libertação e proteção de prisioneiros encarcerados por razões políticas ou religiosas em diferentes partes do mundo.

A data de 28 de maio de 1961 pode ser considerada uma espécie de marco da criação da Anistia Internacional, na medida em que coincide com a publicação do artigo de Peter Benenson, ${ }^{6}$ The Forgotten Prisoners (Os Prisioneiros Esquecidos) no jornal britânico The

3 Informe da Divisão de Segurança e Informações do Ministério da Justiça. 19 de Julho de 1973. BR.AN, RIO.TT.O.MCP.AVU.250. Arquivo Nacional/ RJ.

${ }^{4}$ Sob a peculiar sigla FBI, a Frente Brasileira de Informações, constituiu um movimento de oposição ao regime militar organizado no exterior, sob a liderança de Miguel Arraes, cujas principais ações eram denunciar as violações de direitos humanos que ocorriam nos órgãos de repressão e a política econômica do regime militar que não privilegiava a distribuição de renda. Ver: CRUZ, F. Frente Brasileño de Informaciones e Campanha: os jornais de brasileiros exilados no Chile e na França (1968-1979) (Dissertação de Mestrado). Faculdade de Filosofia, Letras e Ciências Humanas. Departamento de História. Universidade de São Paulo. 2010.

${ }^{5}$ Presidência da República/ Serviço Nacional de Informações. Documento de Informações no. 135/90/AC/72. Data: 22 de setembro de 1972. Amnesty International. Campanha Difamatória contra o Brasil no Exterior, Frente Brasileira de Informações FBI. Anexo: Documento de Informações no 135/90/AC/72 de 22 Set 72 ("AMNESTY INTERNATIONAL" - CAMPANHA DIFAMATÓRIA CONTRA O BRASIL NO EXTERIOR - FRENTE BRASILEIRA DE INFOMAÇÕES - FBI) ao Aviso 348/SI-Gab.

${ }^{6}$ A atuação do advogado britânico filiado ao Partido Trabalhista, Peter Benenson, em organismos da sociedade civil britânica de defesa de presos políticos remonta a 1947, quando foi requisitado pela 


\section{Observer. Trata-se do primeiro "manifesto" da campanha Amnesty, que conclamava} aqueles que condenavam o encarceramento arbitrário e a tortura a se unirem em torno de um objetivo comum:

Abra o seu jornal em qualquer dia da semana e você encontrará uma notícia de algum lugar do mundo a respeito de alguém ter sido encarcerado, torturado ou executado porque suas opiniões ou religião são inaceitáveis para seu governo. (...) O leitor de jornal é acometido de um sentimento de impotência. Se ainda assim esses sentimentos de repugnância presentes em todo o mundo pudessem ser reunidos em uma ação comum, algo efetivo poderia ser feito. (...)

Estabelecemos um escritório em Londres para coletar informação sobre nomes, números e condições do que decidimos chamar Prisioneiros da Consciência e os definimos assim: 'qualquer pessoa impedida (por encarceramento ou outra forma) de expressar (sob palavras ou símbolos) uma opinião na qual ela honestamente acredita e que não defende o uso da violência. ${ }^{7}$

Federação de Sindicatos do Reino Unidos (Trades Union Congress) para assistir a um julgamento político na Espanha. A partir daí, Benenson deu início a uma trajetória de envolvimento em atividades de solidariedade com prisioneiros políticos de diferentes partes do mundo, mas ainda no âmbito de suas atividades como advogado. Assim, em 1959, Benenson esteve diretamente envolvido na defesa de opositores de Franco, ajudando a fundar a organização Spanish Democrats' Defence Fund Committee ligada ao Partido Trabalhista -, que tinha por objetivo angariar fundos para que os opositores do regime franquista tivessem um julgamento justo. O advogado britânico ajudou a criar também, em 1956, a JUSTICE (Joint Union of Societies to Insure Civil Liberties in England and Elsewhere), uma organização internacional multipartidária reunia advogados encarregados de atuar como observadores de julgamentos políticos em diferentes países do mundo. A JUSTICE, por se tratar de uma organização com abrangência internacional e que tinha como objetivo a defesa de prisioneiros políticos, pode ter servido como inspiração para a criação da Anistia Internacional anos mais tarde. A insatisfação com os limites da JUSTICE, tida por Benenson como uma organização excessivamente cautelosa e corporativista por ser exclusivamente formada por advogados, o teria levado a pensar em um movimento de perfil mais agregador. Foi assim que concebeu a campanha Amnesty, um movimento que tinha como principal bandeira a defesa dos chamados prisioneiros da consciência. BUCHANAN, T. 'The Truth Will Set You Free': The Making of Amnesty International. In: Journal of Contemporary History. Vol. 37, no. 4 (Oct., 2002), pp. 575-597. Disponível em: www.jstor.org/stable/3180761 Acesso em 15 de agosto de 2011. P. 578-579.

${ }^{7}$ Open your newspaper any day of the week and you find a report from somewhere in the world of someone being imprisoned, tortured or executed because his opinions or religion are unacceptable to his government. (...) The newspaper reader feels a sickening sense of impotence. Yet if these feelings of disgust all over the world could be united into common action, something effective could be done. (...)We have set up an office in London to collect information about the names, numbers and conditions of what we have decided to call Prisoners of Conscience, and we define them thus: 'Any person who is physically restrained (by imprisonment or otherwise) from expressing (in any form of words or symbols) an opinion which he honestly holds and which does not advocate or condone personal violence.' (tradução da autora. The Forgotten Prisoners, http://www.guardian.co.uk/uk/1961/may/28/fromthearchive.theguardian (tradução da autora). Artigo The Forgotten Prisoners, de Peter Benenson de 28 de maio de 1961. Versão resumida se encontra no site do jornal britânico, The Guardian, em http://www.guardian.co.uk/uk/1961/may/28/fromthearchive.theguardian, acesso em 7 de dezembro de 2011. 
Em seu manifesto, Benenson formulou uma das ideias-chave da campanha Amnesty, a saber, a proteção dos chamados "prisioneiros de consciência”, que se tornaria mais tarde uma das marcas de identidade da Anistia Internacional. Definindo-os como indivíduos encarcerados por expressarem (sob palavras ou símbolos) uma opinião na qual honestamente acreditam, os chamados "prisioneiros de consciência", isto é, os prisioneiros pelos quais a Anistia Internacional se declarava disposta a lutar, não poderiam ter recorrido ao uso da violência.

Para o historiador britânico Tom Buchanan, a condenação de meios violentos de luta política não foi, ao menos no momento de elaboração da campanha Amnesty, objeto de controvérsias (BUCHANAN, 2002, p. 585). No entanto, poucos anos após sua fundação, tal restrição logo se tornou objeto de contestação, em parte pelo caso do prisioneiro de consciência Nelson Mandela, que havia sido preso por ter liderado uma campanha não violenta contra as leis do apartheid em 1952, e que, em 1961, tomou parte em um movimento que se preparava para uma rebelião armada e, em 1964, foi condenado à prisão perpétua. De acordo com as regras da Anistia, Mandela poderia ser adotado contanto estivesse envolvido em movimento pacifista, mas, na medida em que havia tomado parte de um movimento armado, sua adoção ${ }^{8}$ passou a ser questionada (LARSEN, 1979, p. 24).

A questão da adoção de presos que haviam recorrido ao uso da violência como forma de luta política foi objeto de discussão entre os membros da Anistia durante um encontro da organização em Canterbury, em setembro de 1964 (LARSEN, 1979, p. 24). Nele, a Anistia Internacional optou por reafirmar a restrição a presos que houvessem recorrido a meios violentos de luta. Dessa forma, Mandela não pôde mais ser considerado prisioneiro da consciência. Ficou, entretanto, decidido que, por razões humanitárias, a Anistia Internacional acompanharia suas condições de detenção.

A questão em torno do uso da violência voltou a provocar controvérsias entre os membros da Anistia durante os anos 1970, dessa vez, na ocasião da prisão dos

\footnotetext{
${ }^{8} \mathrm{Na}$ linguagem da organização, "adotar" um prisioneiro significa reunir recursos financeiros para o recolhimento de informações sobre ele; a redação de cartas com a finalidade de libertá-lo; auxílio material para sua família e para cobrir custos com advogados.
} 
República Federal da Alemanha. A prisão dos principais líderes do grupo foi cercada de tensões. Dentre essas, o fato de que, mesmo em celas de segurança máxima, as lideranças se comunicavam com integrantes de fora da prisão para comandar ações e atentados; as sucessivas greves de fome por melhorias nas condições carcerárias e a morte de um integrante do grupo durante uma dessas greves. Em face desses eventos e também porque o Baader-Meinhof desfrutava de popularidade entre os alemães (POWER, 2002, p. 184), a Seção Alemã da Anistia Internacional começou a demonstrar interesse pelas condições carcerárias dos integrantes do Exército da Fração Vermelha. O fato de a Seção Alemã manifestar interesse pelo grupo em si já constituiria um problema, na medida em que, pelas regras da Anistia, representantes de um país envolvido nas denúncias jamais poderiam ser encarregados de investigá-las. Assim, um representante da Seção Britânica da Anistia Internacional - Paul Oestricher - foi chamado para averiguar denúncias de tortura, mas declarou-as infundadas em dezembro de 1974 (POWER, 2002, p. 184). Em circunstâncias que na época não ficaram esclarecidas, os principais líderes da primeira geração do Baader-Meinhof que estavam presos morreram em suas celas, tendo apenas sobrevivido Irmgard Muller, cujas condições carcerárias seriam objeto de atenção da Anistia Internacional nos anos seguintes.

Ainda na Alemanha, em 1980, a Anistia Internacional acompanhou de perto as condições carcerárias de integrantes do Exército da Fração Vermelha e do Movimento de 2 de Junho, grupos que sabidamente recorriam a atentados como forma de luta política. Este cuidado pode ser atestado pelo dossiê que a Anistia Internacional publicou naquele ano sobre as condições carcerárias de presos políticos na República Federal da Alemanha entre os anos de 1977 e $1980 .{ }^{9}$ No dossiê, a organização considerou que o isolamento a que os presos políticos alemães foram submetidos eram formas de tortura ou tratamento cruel e desumano. De acordo com o dossiê, as maiores vítimas do isolamento foram

\footnotetext{
${ }^{9}$ Amnesty International's work on prison conditions of persons suspected or convicted of politically motivated crimes in the Federal Republic of Germany: Isolation and solitary confinement. London, England: Amnesty International, International Secretariat, 1980. Library of Congress, Washington.
} 
integrantes do Exército da Fração Vermelha e do Movimento de 2 de Junho que, segundo denúncias, teriam permanecido isolados por períodos que ultrapassavam quatro anos. As denúncias incluíam casos de indivíduos confinados em celas com a luz acesa permanentemente, sem janelas e proibidos de qualquer tipo de contato com outros indivíduos ou de socialização.

O que a atitude dos integrantes da Anistia Internacional revela em relação aos casos de Mandela e de integrantes do Baader-Meinhof, especialmente, é que a questão em torno da defesa ou não de presos políticos que houvessem recorrido ao uso da violência estava longe de constituir um consenso entre os integrantes da organização. $O$ tema se mostrou tão controverso a ponto de a Anistia ter publicado um material específico sobre a questão, já em 1976, intitulado "A Anistia Internacional e o uso da violência: uma nota explicativa" (Amnesty International and the use of violence: An explanatory note). ${ }^{10}$ Nele, a Anistia Internacional posicionou-se a favor de que todos os prisioneiros políticos tivessem um tratamento humano e o direito a um julgamento justo, sem distinguir entre os que fizeram uso ou não da violência. Entretanto, a organização procurou reafirmar que apenas os que não houvessem recorrido ao uso da violência poderiam ser considerados "prisioneiros de consciência":

A ideia de que a Anistia Internacional se recusa a dedicar atenção a prisioneiros que recorreram à violência é baseada em um mal-entendido. O trabalho da Al possui agora três aspectos.

1) A libertação dos prisioneiros da consciência (isto é, não violentos);

2) Um julgamento justo dentro de um período de tempo razoável para todos os prisioneiros políticos.

3) O tratamento humano a todos os prisioneiros.

Esses dois últimos aspectos de seu trabalho assumiram crescente importância na medida em que o movimento expandiu. Assim, a Anistia Internacional intervém por meio de uma variedade de técnicas para impedir a imposição da pena de morte, ou tortura, ou maus tratos, de todos os prisioneiros, estejam eles envolvidos com violência ou não. ${ }^{11}$

\footnotetext{
${ }^{10}$ Amnesty International and the use of violence: An explanatory note. London: Amnesty International Publications, 1976.

${ }^{11}$ The reproach that Amnesty International refuses to concern itself with prisoners who have compelled to have resort to violence is based on a misunderstanding. Al's work now has three aspects: 1 ) The release of prisoners of conscience (ie non-violent prisoners); 2) A fair trial within a reasonable time for all political prisoners; 3) The humane treatment of all prisoners. These last two aspects of its work have assumed growing importance as the movement has expanded. Thus, Amnesty International intervenes through a variety of techniques to prevent the imposition of the death penalty on, or the torture or ill-
} 
A maior parte dos presos políticos brasileiros do regime militar dificilmente poderia se enquadrar na categoria de "prisioneiros de consciência”, já que muitos deles, como se sabe, pertenciam a organizações de esquerda que defendiam abertamente a luta armada. Entretanto, a orientação específica da organização sobre a questão e a atuação da Anistia em relação aos presos políticos alemães pertencentes ao Exército da Fração Vermelha já havia aberto precedentes para que presos políticos brasileiros, mesmo que houvessem recorrido à violência, fossem contemplados pelo trabalho da Anistia Internacional. Ela, de fato, trabalhou pela defesa de presos políticos brasileiros e se valeu de algumas ações estratégicas para tal. Dentre elas, pode-se citar: a elaboração de relatórios com denúncias sobre violações de direitos humanos; a divulgação dessas denúncias no exterior; a escrita de cartas a presos políticos; o envio de correspondência às autoridades carcerárias; aos membros do governo brasileiro e, por fim, o que se propõem analisar mais de perto: o envio de correspondência a membros do governo britânico como forma de chamar atenção para o problema da tortura no Brasil.

Uma das estratégias desta organização - de origem inglesa, cuja sede se encontrava em Londres - foi sensibilizar os integrantes do governo britânico sobre o problema da tortura no Brasil. Com esse objetivo, eram enviadas cartas a diferentes instâncias do governo com o intuito de chamar atenção para as violações de direitos humanos e para se obter informações a respeito de presos políticos brasileiros. Examinando a correspondência entre o governo britânico e a Anistia Internacional a respeito de presos políticos brasileiros, foi possível notar que os integrantes da organização viam as visitas oficiais de representantes do governo brasileiro ao Reino Unido como oportunidade para chamar atenção para as denúncias de tortura que chegavam do Brasil. Uma dessas ocasiões foi a visita do Ministro do Comércio do governo Médici, Pratini de Moraes, que esteve no Reino Unido para uma missão entre os dias 24 e 28 de abril de 1972, cuja finalidade era o estreitamento dos laços comerciais entre o Reino Unido e o Brasil.

treatment of, all prisoners, whether involved in violence or not. Amnesty International and the use of violence: An explanatory note. London: Amnesty International Publications, 1976. Library of Congress, Washington. 
Na ocasião da visita de Pratini de Moraes, integrantes da seção britânica da Anistia Internacional enviaram um total de 12 cartas a diferentes instâncias do governo britânico para denunciar as violações de direitos humanos do regime militar. Uma delas foi escrita por um integrante da Seção Britânica da Anistia Internacional chamado Withfiled, que, enfatizando o fato de ser médico, chamou atenção sobre as denúncias de que profissionais da medicina estariam envolvidos com a prática da tortura no Brasil:

Entendo que uma grande missão de comércio, liderada pelo Sr. Pratini de Moraes, visitará esse país entre os dias 24 e 28 de abril.

Muitas pessoas devem estar preocupadas com o fato de estarmos estabelecendo relações mais próximas com o Brasil em um momento em que o governo brasileiro está encarcerando várias centenas de prisioneiros políticos da oposição sem julgamento e submetendo-os a torturas.

Sendo eu próprio medico, estou particularmente preocupado com os relatos de médicos profissionais estarem participando da tortura de presos políticos no Brasil. Eu escrevi aos cinco mais importantes líderes dessa profissão no Brasil sobre essa acusação, pedindo-lhes eu para negá-la ou para expressar o seu desacordo com as autoridades. Eu não recebi qualquer resposta, nem mesmo dos doze ou mais governantes brasileiros aos quais escrevi sobre o Sr. Jose Francisco BERNARDES, um dos prisioneiros políticos com o qual estou preocupado, como membro da Anistia Internacional.

É evidente que o regime no Brasil é cruel e opressivo e não está nem mesmo preocupado em repudiar as acusações que foram feitas. ${ }^{12}$

${ }^{12}$ I understand that a large Brazilian trade mission, headed by Sr. Pratini de Moraes, will be visiting this country from April $24^{\text {th }}$ to $28^{\text {th }}$. Many people must be concerned that we are establishing closer links with Brazil at a time when its government is imprisoning many hundreds of political prisoners opponents without trial and is subjecting them to tortures. Being a doctor myself, I am particularly concerned about reports of the medical's profession's participation in torture of political prisoners in Brazil. I have written to the five most important leaders of the medical profession in Brazil about this allegation, asking them either to deny it or to express their disapproval to the authorities. I received no reply, nor have I received a reply from any of the twelve or more Brazilian officials to whom I have written about sr. Jose Francisco BERNARDES, one of their political prisoners for whom I am concerned, as a member of Amnesty International. I would suggest that Brazil should be asked to demonstrate a change of direction in the field of human rights and political freedom before closes links can be established with Britain. It is evident that the regime in Brazil is cruel and oppressive and it is not even concerned to repudiate the allegations, which have been made. (1723) Carta de Withfield ao Ministro do Comércio e Indústria (Minister for Trade and Industry), Maurice MacMillan. 11 de abril de 1972. Activities of Amnesty International in Brazil. Foreign Office Records. FCO 7/2205. National Archives, Londres. 
Withfiled, além de ter escrito ao governo britânico, escreveu ao próprio Ministro Pratini de Moraes:

Estou particularmente preocupado, sendo eu mesmo médico, com os relatos de profissionais da medicina participarem no Brasil de tal tortura. Eu escrevi aos cinco mais importantes líderes dessa profissão no Brasil sobre essa acusação, pedindo-lhes para comentar as acusações. Novamente, não obtive resposta, o que sugere que elas não podem ser negadas. $^{13}$

Na mesma ocasião, outro integrante da Seção Britânica da Anistia Internacional, chamado J. R. Blanco, procurou sensibilizar integrantes do governo britânico para o problema da tortura em prisões brasileiras no momento em que a missão do Ministro Pratini buscava estreitar laços comerciais com o Reino Unido. Como na escrita por Withfield, o argumento mobilizado por Blanco é o de que Grã-Bretanha não poderia estabelecer ou aprofundar relações comerciais com um país como o Brasil, que violava direitos humanos. Além de criticar o governo britânico pelo estabelecimento de relações comerciais com um país que violava direitos humanos, Blanco se valeu de outra estratégia discursiva para chamar a atenção das autoridades britânicas sobre as denúncias de tortura no Brasil. Ele optou por expor o contraste entre duas imagens opostas existentes sobre o Brasil no exterior - a de país democrático com uma economia em expansão e aquela de um país, cujo governo violava os direitos humanos de presos políticos:

Entendemos que uma missão de comércio encabeçada pelo Sr. Marcus Pratini de Moraes, Ministro do Comércio, se encontra nesse momento no Reino Unido.

O Brasil é uma nação ambiciosa com uma economia em rápida expansão e gosta de se considerar uma grande democracia como as demais nações ocidentais. Contudo, no campo da justiça e direitos humanos, não há nesse momento sinal de melhora em relação à severa repressão conduzida pelo General Médici nos últimos anos.

A Anistia Internacional possui mais de 180 casos ativos envolvendo prisioneiros da de consciência brasileiros e informações (em investigação) sobre centenas de outros casos.

\footnotetext{
${ }^{13}$ I am particularly concerned, being a doctor myself, about the reports of the medical profession in Brazil in participating in such torture. I have written to five leading members in your country, asking them to comment on the allegations. Again, I have received no reply, which suggest that they cannot be denied. (1756) Carta de Withfield a Pratini de Moraes. 11 de abril de 1972. Activities of Amnesty International in Brazil. Foreign Office Records. FCO 7/2205. National Archives, Londres.
} 
Tem havido relatos recorrentes, até mesmo na imprensa brasileira, de tortura e outros maus tratos a prisioneiros. Recentemente a pena de morte foi introduzida para crimes políticos.

Esse grupo acompanhou de perto o caso de um prisioneiro, em particular, que foi condenado por um tribunal militar por atividade política alguns anos antes de sua prisão. ${ }^{14}$

\section{Blanco ainda criticou o fechamento do "Conselho Brasileiro pela Defesa dos}

Direitos Humanos", que muito provavelmente se tratava do Conselho de Defesa dos Direitos da Pessoa Humana (CDDPH), que fora criado em março de 1964 por decreto assinado pelo presidente João Goulart:

Em correspondência com a Embaixada britânica no Brasil, soubemos que o Conselho Brasileiro pela Defesa dos Direitos Humanos não está mais em atividade desde a supressão da oposição.

A Comissão Internacional de Juristas também relatou a natureza insatisfatória dos tribunais militares e a falta de solução nas cortes civis. ${ }^{15}$

\section{A existência do Conselho de Defesa dos Direitos da Pessoa Humana (CDDPH) se} tratava de uma das muitas ambiguidades do regime militar brasileiro (SAFATLE; TELES, 2010. p. 262). Contudo, conforme confirma a carta de Blanco, o referido Conselho já não se encontrava mais em atividade, e, em janeiro de 1972, o Movimento Democrático Brasileiro

14 (tradução da autora) We understand that a Trade Mission handed by Mr. Marcus Pratini de Moraes, Minister of commerce, is at present visiting the U.K. Brazil is an ambitious nation with a rapidly expanding economy and likes to considered as a great democracy on a ? with the major Western nations. However, in the field of justice and human rights there is at present no sign of improvement over the severe repression on which has marched General Medici's role in recent years. Amnesty International has over 180 active cases involving Brazilian prisoners of conscience and basic information (under investigation) on hundreds of others. There have been persistent reports, reflected even in the Brazilian press, of torture and other mal-treatment of prisoners. Quite recently, the death penalty has been introduced for political offences. This group has dealt in detail with the case of one particular prisoner who was sentenced by a military tribunal for political activity several years before his arrest. Carta de J R. Blanco ao Foreign Office. (1704) 26 de abril de 1972. Activities of Amnesty International in Brazil. Foreign Office Records. FCO 7/2205. National Archives, Londres.

${ }^{15}$ (tradução da autora). In correspondence with the British Embassy in Brazil, we learnt that the Brazilian Council for the Defense of Human Rights is no longer active since the suppression of the opposition. The International Commission of Jurists has also reported on the unsatisfactory nature of military tribunals and the lack of remedy in the civilian courts. I hope that you will appreciate that we are not concerned with people accused of violence or pro-terrorists activities (there are clearly some Law and other problems in some remote areas of Brazil) but with cases which with after investigation have been found to be purely political in the national democratic sense. I would suggest that Brazil should asked to demonstrate a change of direction in the field of human rights and political freedom before closer links can be established with Britain. (1704) Carta de J R. Blanco ao Foreign Office. 26 de abril de 1972. Activities of Amnesty International in Brazil. Foreign Office Records. FCO 7/2205. National Archives, Londres. 
(MDB) já havia se retirado do CDDPH, alegando que ali não se apuravam as denúncias de tortura e abuso de direitos humanos (SAFATLE; TELES, 2010. p. 262).

Mais adiante, ainda na mesma carta, Blanco recorreu a outro argumento para legitimar suas denúncias. Enfatizou o fato de estar agindo em nome de presos políticos que não recorreram à violência para a defesa de suas ideias:

Eu espero que note que não estamos agindo em nome de pessoas acusadas de violência ou atividades pró-terrorismo (claramente, há problemas relacionados à Lei e outros em algumas áreas remotas do Brasil), mas com casos que, após investigação, mostraram-se puramente políticos no sentido democrático.

Eu sugeriria que se demandasse do Brasil uma demonstração de mudança de direção no campo dos direitos humanos e liberdade política antes que relações mais próximas fossem estabelecidas com a GrãBretanha. ${ }^{16}$

Distinguir a defesa dos prisioneiros que não haviam recorrido à violência não se tratava apenas de uma estratégia discursiva para qualificá-los positivamente aos olhos de um membro do governo britânico, mas de afirmar uma posição coerente com os princípios da Anistia Internacional.

Quem respondeu à carta de Blanco foi o Secretário de Comércio e Indústria do Reino Unido, John Davies, afirmando que a visita de Pratini ao Reino Unido tinha um caráter exclusivamente privado e, por consequência, o governo britânico não estaria envolvido. De maneira polida, Davies procurou salientar que apreciava o interesse da Anistia Internacional pelas condições carcerárias de prisioneiros políticos brasileiros, mas que o governo britânico não tinha condições de intervir em questões internas do Brasil. ${ }^{17}$ Blanco considerou insatisfatória a postura não-intervencionista por parte do governo

\footnotetext{
${ }^{16}$ (tradução da autora) I hope that you will appreciate that we are not concerned with people accused of violence or pro-terrorists activities (there are clearly some Law and other problems in some remote areas of Brazil) but with cases which with after investigation have been found to be purely political in the national democratic sense. I would suggest that Brazil should asked to demonstrate a change of direction in the field of human rights and political freedom before closer links can be established with Britain. Carta de J R. Blanco ao Foreign Office. 26 de abril de 1972. Activities of Amnesty International in Brazil. Foreign Office Records. FCO 7/2205. National Archives, Londres.

17 John Davies \& Anthony Kershaw. Brazil/Amnesty International. 8 de maio de 1972. Activities of Amnesty International in Brazil. Foreign Office Records. FCO 7/2205. National Archives, Londres.
} 
Fiquei muito surpreso ao saber que o Ministério das Relações Exteriores entende a visita do Senhor Pratini de Moraes como exclusivamente privada e não envolvendo o Governo. O tamanho dessa delegação e a quantidade de publicidade que a antecedem mostram que o governo brasileiro não a vê como uma questão privada.

De acordo com notícias recentes da imprensa, o objetivo da delegação não é apenas de aumentar as exportações brasileiras, mas para seduzir o capital estrangeiro para o Brasil também. (...)

Blanco ainda utilizou dois argumentos distintos para defender a ideia de que o governo britânico poderia e deveria manifestar repúdio às violações de direitos humanos no Brasil. Em primeiro lugar, argumentou que tanto o Brasil quanto o Reino Unido, por se tratarem de nações em tese comprometidas com a Declaração Universal de Direitos Humanos da Organização das Nações Unidas, deveriam zelar por seus princípios e artigos:

Enquanto o Governo Britânico não pode intervir diretamente no sistema judicial brasileiro (ou em seus abusos), ambos os governos são comprometidos com a Declaração de Direitos Humanos da ONU, que afirma que a promoção desses princípios é preocupação de "cada indivíduo e cada órgão da sociedade" entre os Estados membros."

Embora o Brasil no momento apresente muitas das características de uma ditadura militar, trata-se de uma nação voltada para o exterior, sensível às opiniões estrangeiras e muitas vezes atua procurando recomendações das potências ocidentais estabelecidas. ${ }^{18}$

Em seu segundo argumento, Blanco procurou ressaltar que o Brasil, embora apresentasse características que permitiram defini-lo a como uma ditadura militar,

\footnotetext{
${ }^{18}$ I was very surprised to hear that the Foreign Office regards Senhor Pratini de Moraes' visit as purely private and not involving the Government. The size of this trade delegation and the amount of advance publicity show that Brazilian Government does not regard it as a private matter. According to recent press reports, the aim of the delegation is not only to boost Brazilian exports but to tempt foreign capital to Brazil also. While the British Government cannot intervene directly in the Brazilian judicial system (or its abuse) both governments are bound by the U.N. Declaration of Human Rights which states that the promotion of these principles is the concern of "every individual and every organ of society" within the Member States. Although Brazil at present shows many of the characteristics of a military dictatorship, she is an outward-looking nation, sensitive to foreign opinions and often acting seeking advice from the established Western Powers. (1694). Carta de Blanco a John Davies. 16 de maio de 1972. Activities of Amnesty International in Brazil. Foreign Office Records. FCO 7/2205. National Archives, Londres.
} 
tratava-se de uma nação particularmente sensível à sua imagem no exterior, sobretudo diante das potências ocidentais. Essa peculiaridade do país poderia, conforme argumentou Blanco, fazer com que o governo brasileiro cedesse a pressões internacionais de países proeminentes do cenário comercial internacional como o Reino Unido. De fato, o governo brasileiro tinha razão em se preocupar com sua imagem no Reino Unido, onde as denúncias de violações de direitos humanos pareciam repercutir tanto na imprensa quanto na opinião pública britânicas. A correspondência entre a Embaixada Britânica em Brasília e o Foreign Office referente ao ano de 1972 sugere que a repercussão na imprensa britânica sobre o tratamento dispensado a presos políticos brasileiros era objeto de constrangimento no que diz respeito às relações diplomáticas entre os dois países:

Durante a visita do Sr. Godber ao Brasil, o embaixador brasileiro em Londres disse que há algum tempo vem tentando achar alguma desculpa para que o Ministro da Justiça (...) visite a Grã-Bretanha. Parece que há algum tempo o Dr. Buzaid tem querido vir à Grã-Bretanha. O Sr. Correa da Costa disse que ele pensou que o Ministro desejaria que tal visita fosse informal, com menos publicidade possível, sugerindo que isso seria devido ao interesse da imprensa britânica pelo tratamento dado aos presos políticos no Brasil (esse assunto recai sob a responsabilidade do Ministro).

Em virtude do caráter delicado que a questão dos presos políticos tem tido na Grã-Bretanha no momento, o Sr. Godber não está muito preocupado em responder, a não ser com banalidades, caso o Sr. Costa volte a esse assunto. Se os brasileiros pressionarem sugerindo que $\mathrm{o}$ Ministro da Justiça visite a Grã-Bretanha, nós teríamos que responder, mas nesse momento seria provavelmente melhor que ele não viesse. ${ }^{19}$

\footnotetext{
${ }^{19}$ During Mr. Godber visit to Brazil, the Brazilian Ambassador in London said that he had for some time been trying to find an excuse for the Minister of Justice, who as you know is ex-officio the senior minister in Brazil, to visit Britain. It seems that Dr. Buzaid has for some time wanted to come to Britain. Sr Correa da Costa said that he thought that the Minister would wish any such visit to be informal with as little publicity as possible, implying that this was because of British press interest in the treatment of political prisoners in Brazil (this subject falls with the Minister's responsibilities. Because of the sensitivity of the political prisoners issue in Britain at present, Mr. Godber is not too eager to respond with anything more than platitudes if Sr. Costa should return to this subject. If the Brazilians should press the suggestion that this Minister of Justice should visit Britain, we would clearly have to respond but at present, it would be probably be better if he did not come. (1656) POSSIBLE VISIT TO LONDON OF BRAZILIAN MINISTER OF JUSTICE. Carta da Embaixada Britânica em Brasília ao Foreign Office. Carta confidencial de M. I. Goulding a J. M. Hunter. 11 de setembro de 1972. Activities of Amnesty International in Brazil. Foreign Office Records. FCO 7/2205. National Archives, Londres.
} 
A correspondência entre os funcionários do Foreign Office e da Embaixada Britânica no Brasil ainda sugere que a preocupação com os presos políticos brasileiros atingia não somente a imprensa britânica, mas também o Parlamento:

Tem havido uma preocupação crescente no Parlamento e da opinião pública com o tratamento de presos políticos no Brasil. Qualquer missão ao Brasil ou do Brasil geralmente aumenta a pressão. Precisamos então estar preparados para mais desdobramentos em relação à visita de Godber ao Brasil. Os brasileiros estão naturalmente sensíveis a essa crítica e isso não poderia ajudar as relações entre brasileiros e britânicos. Seria muito difícil levantar esse assunto com eles, mas eles o fazem ao reclamarem sobre a imprensa britânica. ${ }^{20}$

A preocupação de Hunter, particularmente, dizia respeito à visita do Ministro das Relações Exteriores do governo britânico ao Brasil. De fato, os integrantes da Anistia Internacional viam visitas oficiais como as de Godber ao Brasil como uma oportunidade para chamar atenção para as denúncias de tortura que chegavam do Brasil. Assim, às vésperas da visita de Godber, os integrantes da Anistia Internacional procuraram lhe escrever. A carta abaixo, escrita por uma integrante da Seção Britânica da Anistia Internacional, Sra. Coyle, foi uma das treze cartas enviadas pela Anistia ao Ministro Godber:

Como membro da Anistia, preocupada com o bem-estar de um prisioneiro político brasileiro, tem me causado impressão os relatos persistentes de tortura e de prisões arbitrárias recebidos do Brasil nos últimos anos. Tanto a Cruz Vermelha quanto a Anistia requisitaram por mais de uma vez permissão para visitar as prisões brasileiras, com o objetivo de determinar objetivamente se esses relatos são verdadeiros. As autoridades brasileiras recusaram.

Muitos brasileiros proeminentes consideram que a situação necessita de uma ampla investigação, mas seus protestos até agora resultaram em uma Comissão de Defesa de Direitos Humanos ameaçada e obrigada a se encontrar secretamente.

\footnotetext{
${ }^{20}$ There has been increasing concern in Parliament and from members of the public about the treatment of political prisoners in Brazil. Any major visit to or from Brazil usually increases the pressure. We must therefore be prepared for further expressions of concern arising out of Mr. Godber's visit to Brazil. The Brazilians are naturally sensitive to such criticism, and it cannot help Anglo-Brazilian relations. It would be very difficult to raise the subject with them, but they do so themselves by complaining particularly about the attitude of British press. Carta de J. M. Hunter a Mr. Goulding. Brazil - Treatment of Political Prisoners. 22 de agosto de 1972. (1661) Activities of Amnesty International in Brazil. Foreign Office Records. FCO 7/2205. National Archives, Londres.
} 
Entendendo a importância da sua missão, muitos britânicos abominariam o estreitamento desses laços, até mesmo econômicos, enquanto acusações de tortura e maus-tratos são ignoradas pelo governo brasileiro.

Eu pediria para interceder em particular em nome de Cleomenes de Paula RIBIERO, prisioneiro adotado por este Grupo. Ele foi preso em maio de 1970 sem acusação ou julgamento. Estamos sem poder afirmar onde ele está detido ou mesmo se ele já foi libertado. ${ }^{21}$

Dois outros integrantes da Seção Britânica da Anistia Internacional escreveram ao Ministro britânico para que intercedesse a favor do caso de Ênio Silveira, que comandava a Civilização Brasileira, uma das mais importantes editoras no Brasil. ${ }^{22}$ Ênio Silveira havia sido indiciado pelo Superior Tribunal Militar (STM) em três Inquéritos Policiais Militares e a Editora Civilização Brasileira havia sofrido dois atentados a bomba, um dos quais a fez perder sua sede e sua livraria na Rua Sete de Setembro, no Rio de Janeiro. ${ }^{23}$

Recentemente alguns relatos têm circulado denunciando tortura e prisões arbitrárias no Brasil. Pedidos da Anistia Internacional e da Cruz Vermelha Internacional para investigar a veracidade desses relatos foram recusados pelo Governo Brasileiro.

As questões deveriam ter sido tratadas no Conselho pela Defesa dos Direitos Humanos, conforme estabelecido por lei. Isso não ocorreu e a reestruturação recente parece tornar a investigação menos provável.

Nós gostaríamos que vocês investigassem esses relatos de tortura e prisões arbitrárias enquanto estiverem no Brasil. Nós também pediríamos que a Grã-Bretanha tenha cautela em relação ao aumento do comércio com o Brasil enquanto essas denúncias permanecerem sem resposta.

${ }^{21}$ As a member of Amnesty, concerned with the welfare of a Brazilian political prisoner, I have been disturbed by the persistent reports of torture and arbitrary arrest, which have been received from Brazil over the past several years. Both the Red Cross and Amnesty have repeatedly requested permission to visit Brazilian prisons in order to determine objectively whether such reports are true. The Brazilian authorities have refused. Many prominent Brazilians feel that the situations needs a full investigation but their protests have so far resulted in a Defense of Human Rights being pared down and having to meet in secret. Carta de Mrs. Whilst understanding the importance of your mission, many British people would abhor the strengthening of links, even economic, whilst allegations of torture and ill-treatment, are ignored by the Brazilian Government. I would particularly ask that you intercede on behalf of Cleomenes de Paula RIBIERO, a prisoner adopted by this Group. He was arrested in May 1970, without charge or trial. We are unable to ascertain where he is being held or even whether he has been released. Carta da Sra. Coyle ao Ministro. Godber. 27 de fevereiro de 1972. (1792) Activities of Amnesty International in Brazil. Foreign Office Records. FCO 7/2205. National Archives, Londres.

${ }^{22}$ A Revista Civilização Brasileira, publicação da Editora de mesmo nome, era coordenada por um conselho editorial composto por uma maioria de membros do PCB. CZAJKA, R. A Revista Civilização Brasileira: Projeto Editorial e Resistência Cultural (1965-1968). In: Revista de Sociologia e Política. V. 18 no. 35: 95-117. Fev. 2010. p. 96.

${ }^{23}$ CZAJKA, R. A Revista Civilização Brasileira: Projeto Editorial e Resistência Cultural (1965-1968). In: Revista de Sociologia e Política. V. 18 no. 35: 95-117. Fev. 2010. pp. 109-111 
Em particular, gostaríamos de trazer o caso de Ênio Silveira, antigo diretor da Associação Brasileira de Imprensa e até sua prisão no início de 1970, diretor da Editora Civilização Brasileira SA, Rua Sete de Setembro, 97, Rio de Janeiro. O Sr. Silveira foi até o momento preso quatro vezes e foi duas vezes a julgamento sem condenação. Em 18 de fevereiro de 1972 estava previsto que fosse novamente levado a julgamento perante um Tribunal Militar no Rio de Janeiro. Acreditamos, que como das outras vezes, a acusação será de crime contra a segurança nacional e relacionada à publicação de um livro. Além desses julgamentos, parece que o Sr. Silveira e sua firma sofreram intimidações.

Nós pedimos a vocês para pôr fim ao presente julgamento contra o Sr. Silveira e que ele tenha liberdade para publicar. ${ }^{24}$

As respostas do Foreign Office e de seu Departamento para a América Latina às cartas endereçadas a Godber mostram que o Ministro não chegou a realizar a visita programada ao Brasil, prevista para o primeiro semestre de 1972, pois sua viagem à América do Sul teria sido encurtada. O Foreign Office argumentou que, mesmo que ele tivesse ido, teria sido difícil que Godber abordasse as denúncias de tortura, já que, em tese, seria um problema interno do Brasil, sobre o qual o governo britânico não teria condições de intervir. ${ }^{25}$ Somente no caso de Ênio Silveira, o Foreign Office afirmou ter informações a este respeito e respondeu aos integrantes da Anistia Internacional que o editor havia sido julgado por uma corte militar e que havia sido libertado. ${ }^{26}$

${ }^{24}$ Recently a number of reports have been circulating alleging torture and arbitrary arrestments in Brazil. Requests to investigate the truth of these reports by both Amnesty International and the International Red Cross have been refused by the Brazilian Government. The matters should have been dealt with the Council for the Defence of Human Rights as act out by law. This has not happened and recent restructuring seems to make effective investigation less likely. We would like to urge that you investigate these reports of torture and arbitrary arrest while in Brazil. We would also like to request that Britain be wary of increasing Trade with Brazil while these very serious allegations remain unanswered. In particular, we would like to raise the case of Enio Silveira a past head of the Brazilian Publishers Association and until his arrest in early 1970 head of the publishing from Editora Civilização Brasileira SA rua 7 de setembro 97 Rio de Janeiro. Sr. Silveira has now been arrested 4 times and has twice previously been brought to trial without conviction on Feb $18^{\text {th }} 1972$. S. Silveira was due to be brought to trial before a Military Tribunal in Rio de Janeiro. We believe that as before, the charge will be as it was crimes against national security and relate to the publishing of a book. Apart from these trials, it appears that both Sr. Silveira and his firm have suffered intimidation. We appeal to you to request cessation of the current trial against Sr. Silveira and also that he be allowed freedom to publish. (1766) Carta de Lowther-Harris a Godber. 2 de março de 1972. Activities of Amnesty International in Brazil. Foreign Office Records. FCO 7/2205. National Archives, Londres.

${ }^{25}$ Activities of Amnesty International in Brazil. Foreign Office Records. FCO 7/2205. National Archives, Londres.

${ }^{26}$ (1765) Activities of Amnesty International in Brazil. Foreign Office Records. FCO 7/2205. National Archives, Londres. 
O que os documentos analisados até aqui sugerem é que a repercussão negativa sobre o regime militar brasileiro parece ter atingido seu ponto máximo no Reino Unido durante o ano de 1972. Tal repercussão negativa se deu muito provavelmente em função da publicação do relatório da Anistia Internacional sobre a tortura no Brasil (Report on Allegations of Torture in Brazil). ${ }^{27}$ A publicação do relatório foi noticiada pelos jornais britânicos Times, em 6 de setembro de 1972, e International Herald Tribune, em 9 de setembro de $1972 .{ }^{28}$ Os artigos de ambos os jornais dizem que o relatório cobria denúncias recebidas entre os meses de dezembro de 1968 e julho de 1972 e buscaram salientar sua principal conclusão, isto é, a constatação de que a tortura no Brasil era praticada de maneira sistemática pela polícia e órgãos de segurança como forma de investigação de crimes políticos e de intimidação da população.

\section{Da compaixão à ação}

A Anistia Internacional, ao contrário do que o serviço de informação do regime militar brasileiro considerou, não integrava o que os militares brasileiros chamaram de “Movimento Comunista Internacional." Na verdade, ao se olhar mais de perto para as origens da organização, percebe-se que ela foi criada com base em um sentimento de desilusão com as instituições e ideologias políticas, algo muito em voga no pós-guerra europeu. É o que revela a correspondência entre seus fundadores, Peter Benenson e Eric Baker, pouco antes do lançamento da campanha Amnesty, que deu origem à organização em maio de 1961. Em carta dirigida a Eric Baker, que data de 1960, portanto, antes do lançamento da campanha Amnesty, Benenson defendeu a ideia de que a transformação do mundo dependeria menos do que poderia ser feito na dinâmica política de partidos e eleições e mais das possibilidades de transformação do mundo a partir dos impulsos e

\footnotetext{
${ }^{27}$ Report on Allegations of Torture in Brazil. Relatório sobre as Acusações de Tortura. Anistia Internacional. 1972. 92 fls. 50-Z-30-4017. Fundo Deops/SP. Série dossiês. Arquivo Público do Estado de São Paulo (APESP).

${ }^{28}$ Recorte de jornal. Times. 6 de setembro de 1972. Artigo intitulado “Amnesty report names Brazilian 'tortures'. Assinado por Clifford Longley. (1654) Recorte de Jornal. International Herald Tribune. 9 de setembro de 1972. Artigo intitulado "Amnesty International Details Charges of Torture". Assinado por Joseph Collins. (1653). Activities of Amnesty International in Brazil. Foreign Office Records. FCO 7/2205. National Archives, Londres.
} 
sentimentos individuais. Sugeria, assim, que o caminho para a promoção da justiça social estaria na esfera espiritual do indivíduo, enquanto as tentativas de construção de uma sociedade justa a partir da transformação do “externo" estariam destinadas ao fracasso:

Só o tempo pôde confirmar minha crescente convicção de que a busca por um Reino [de Deus] externo e visível é equivocada... A tentativa de construir uma sociedade justa alterando o externo está fadada ao fracasso (...) Quando cada cidadão se encontra individualmente no caminho do Reino, aí acredito que haverá uma sociedade justa na Terra, sem a necessidade de intervenção do Parlamento. E se ao menos alguns dos nossos cidadãos trilhassem esse caminho, então eu acredito que estaríamos mais perto do objetivo do que se $51 \%$ dos eleitores votasse por leis destinadas à promoção de justiça social. ${ }^{29}$

$\mathrm{Na}$ origem da criação da Anistia, portanto, estava presente a visão de que a transformação do mundo deveria se dar a partir da esfera íntima do indivíduo e não no âmbito da esfera política, sentimento esse em parte motivado pela desilusão com o socialismo. É o que revela o documento 'First Notes on Organisation', de 5 de junho de 1961, escrito por Benenson:

O propósito subjacente a essa campanha - que eu espero que aqueles que estão conectados a ela irão lembrar - mas nunca publicar - é encontrar uma base comum sobre a qual os idealistas do mundo possam cooperar. Ela foi elaborada em particular para absorver o entusiasmo latente do grande número desses idealistas que, desde o eclipse do socialismo, se tornaram cada vez mais frustrados. ${ }^{30}$

Portanto, na origem da campanha Amnesty, esteve presente um sentimento difuso de decepção em relação às instituições e ideologias políticas, que se traduziu na busca por

29 "Time here, alone, has confirmed my growing conviction that the quest for an outward and visible Kingdom [of God] is mistaken... The attempt to construct a just society by altering the external framework is, I am sure, doomed to failure. (...) When each citizen is individually on the road to the Kingdom, then I believe that there will be a just society on earth without need for the intervention of Parliament. And if only a few of our leading citizens trod that path, then I believe that we would be nearer the goal than if $51 \%$ of the electors voted for laws designed to promote social justice." (Tradução da autora). Carta de Peter Benenson para Eric Baker, de 26 de março de 1960, que integra a correspondência entre os membros fundadores da organização Anistia Internacional. BENENSON, P. Apud BUCHANAN. T. Ibidem. p. 582

30 The underlying purpose of this campaign - which I hope those who are closely connected with it will remember, but never publish - is to find a common base upon which the idealists of the world can cooperate. It is designed in particular to absorb the latent enthusiasm of great numbers of such idealists who have, since the eclipse of Socialism, become increasingly frustrated. 'First Notes on Organisation'. 5 de junho de 1961. BUCHANAN, T. 'The Truth Will Set You Free': The Making of Amnesty International. In: Journal of Contemporary History. Vol. 37, no. 4 (Oct., 2002), pp. 575-597. Disponível em: www.jstor.org/stable/3180761 Acesso em 15 de agosto de 2011. p. 593. 
é, as guerras étnicas provocadas pelo deslocamento de milhões de civis - entre repatriados, refugiados e reassentados - colaboraram para sedimentar um sentimento de desilusão em relação à civilização ocidental. Na raiz da desilusão não estava apenas o Nazismo alemão, mas também as atitudes das forças aliadas "liberais" e "democráticas", que não hesitaram em bombardear alvos civis e a demonstrar a força de seu potencial atômico. E, se ainda havia alguma expectativa de que o socialismo soviético poderia direcionar a civilização ocidental a outra direção, o discurso de Khrushchev ao Partido Comunista da União Soviética (PCUS), em 1956, ao expor ao mundo os crimes de Stálin, contribuiu para a descrença de que o socialismo soviético pudesse condensar os ideais de transformação do mundo. ${ }^{31}$

Em um momento de profunda desilusão com as instituições e ideologias políticas, a religião pareceu a muitos como uma resposta para preservação dos valores da civilização ocidental (CHIBA, 1995). Para salvaguardar a humanidade da violência e para promover justiça social, constituíram-se as mais diversas formas de dar sentido à vida por meio da esfera espiritual do indivíduo, fundamentalmente por meio da mobilização do sentimento de compaixão (CANCELLI, 2011, p. 9). Como expressão disso, ao longo do século XX, organizações de caráter humanitário, como o Comitê Internacional da Cruz Vermelha (International Committe of the Red Cross), Oxford Committee for Famine Relief (OXFAM), Moral Re-Armament (MRA), Médico Sem Fronteiras (MSF), Action Contre La faim (ACF) expandiram suas atividades e o raio de alcance de suas ações. Na origem dessas organizações de fundo humanitário estava também a percepção de que o imperialismo europeu teria contribuído para a desordem política nos continentes africano e asiático e, a

\footnotetext{
${ }^{31}$ Sob o impacto das revelações de Nikita Khrushchev durante o vigésimo Congresso do Partido Comunista da União Soviética, em 1956, quando Khrushchev expôs os crimes de Stálin, acusando-o de ignorar princípios leninistas, muitos daqueles que ainda depositavam esperanças no socialismo soviético acabaram por abandonar os partidos comunistas. A exemplo disso, o Partido Comunista Italiano sofreu baixas de 400 mil membros entre os anos de 1955 e 1957, movimento que se seguiu na França e Grã-Bretanha. A repressão às pressões por reformas na Hungria, em 1956, que terminaram na morte de 2700 húngaros, a condenação à morte de 341 e a prisão de 22 000, também colaborou para sedimentar, aos poucos, um profundo sentimento de desilusão em relação ao comunismo. Ver: (JUDT, 2005, pp. 310-318)
} 

apenas ao fortalecimento das religiões de maneira institucionalizada, mas também, ao que aqui se deseja olhar mais de perto, ao surgimento e expansão de um grande número de organizações privadas, no âmbito da sociedade civil, comprometidas com valores espirituais, como a Anistia Internacional.

Quando se olha mais de perto para o trabalho da Anistia Internacional, é possível identificar uma espécie de padrão em seu modo de atuação. Por meio da análise da correspondência da Anistia Internacional aqui mostrada, percebe-se que, em cada uma das cartas, intercede-se a favor de um indivíduo. Por mais que as cartas aqui analisadas também contenham críticas dirigidas ao governo brasileiro ou ao problema da tortura de maneira mais geral, têm como objetivo principal a obtenção de informações sobre um prisioneiro específico. A preocupação com o estado de um indivíduo em especial constitui um traço distintivo perceptível em todas as cartas escritas por membros da Anistia.

A atenção direcionada ao indivíduo constituiu uma estratégia de ação própria da Anistia Internacional coerente com a orientação estabelecida desde a sua criação. A Anistia começou como um movimento internacional, cuja ideia, em princípio, era que se formassem grupos de três pessoas que seriam responsáveis pela adoção de três prisioneiros, sendo cada um destes obrigatoriamente pertencentes respectivamente ao “Ocidente", “Oriente” e "Terceiro Mundo" ou “mundo em desenvolvimento" para que a organização tivesse uma atuação "neutra" e "imparcial” que, em tese, contemplasse igualmente prisioneiros dos blocos comunista, capitalista e de países não alinhados. Cada grupo da Anistia é responsável pelo acompanhamento de um ou mais indivíduos, aos quais são enviadas cartas que buscam interceder a favor de um prisioneiro específico, na tentativa de obter informações a seu respeito.

Portanto, pode-se dizer que um traço do movimento que poderia diferenciá-lo em relação a outras campanhas ou organizações políticas foi a atenção dispensada ao indivíduo, princípio que nortearia as ações da Anistia ao menos até a década de 1980.

\footnotetext{
${ }^{32}$ Em muitos casos, havia a esperança de diminuir a imigração em direção ao continente europeu.
} 
que seria crucial às campanhas e ações, a saber, a compaixão. Para a Anistia Internacional, o apelo à compaixão pareceu determinante para se buscar apoio político e adesão da sociedade civil.

Compreende-se aqui a compaixão que a Anistia Internacional buscou mobilizar para o seu trabalho de libertação de presos políticos seguindo a apreciação sobre esse sentimento proposta por Hannah Arendt. Para Arendt, em função de sua própria natureza, esse sentimento não poderia ser mobilizado pelo sofrimento de uma classe inteira, povo ou pela humanidade como um todo, já que uma singularidade fundamental inerente à linguagem da compaixão seria o fato de poder ser dirigida somente a um indivíduo e não a muitos (ARENDT, 2006, p. 75).

Continuando pelo caminho trilhado por Hannah Arendt, o sentimento de compaixão teria permeado as instituições políticas europeias desde a Revolução Francesa (ARENDT, 2006, p. 69) e teria sido Rousseau o responsável por introduzir a compaixão pela primeira vez na teoria política (ARENDT, 2006, p. 71). Para Arendt, o pensamento de Rousseau - tão comumente associado ao racionalismo iluminista - apelava para a paixão, para o coração e para o que chamou de "alma dilacerada" (âme déchirée):

É como se Rousseau, em sua revolta contra a razão, tivesse posto uma alma bipartida no lugar da dupla alma que se manifesta no diálogo silencioso da mente consigo mesma, que chamamos pensamento. $\mathrm{E}$ como a duplicidade da alma é um conflito, e não um diálogo, ela engendra a paixão em seu duplo sentido de intenso sofrimento e intenso arrebatamento. Foi essa capacidade de sofrimento que Rousseau contrapôs, de um lado, ao egoísmo da sociedade, e do outro, à impassível solidão do espírito entregue a um diálogo consigo mesmo. E foi essa ênfase no sofrimento, mais do que qualquer outra parte de seus ensinamentos que ele deve a enorme e preponderante influência sobre os espíritos dos homens que haveriam de fazer a revolução, e que foram confrontados com os opressivos sofrimentos dos pobres, a quem eles abriram as portas do domínio público e de sua luz, pela primeira vez na história. (ARENDT, 1988, p.64)

E se fora Rousseau o primeiro a introduzir a compaixão no pensamento político, fora Robespierre o primeiro a trazê-la para a esfera política. (ARENDT, 2006, p. 71). Com a 
liberdade ao transformarem a compaixão pelos mais pobres ou a capacidade de "sofrer" ou de "sentir a dor" de outros indivíduos na única força motriz da Revolução capaz de unir as diferentes classes em torno de um objetivo comum (ARENDT, 2006, p. 70).

Arendt, então, procurou distinguir compaixão, pena e solidariedade. Seguindo a própria etimologia da palavra, compaixão significa sofrer a dor do outro, sendo somente possível ser expressa na esfera íntima e apenas por meio de uma linguagem de gestos e expressões, por meio da qual o sofrimento se torna audível e visível no mundo; pena seria a perversão do sentimento de compaixão e, solidariedade, por sua vez, constituiria uma alternativa à compaixão, já que, e na medida em que se trataria de uma atitude "racional", significaria o interesse "desapaixonado" pelos oprimidos e explorados (ARENDT, 2006, p. 79). Assim, mesmo que Robespierre estivesse motivado pelo sentimento de compaixão, sua compaixão teria se corrompido e se transformado em pena no momento em que ele a tornou pública, quando ele não mais conseguiu direcioná-la em direção ao sofrimento específico e focá-lo em indivíduos particulares (ARENDT, 2006, p. 80)

Se Arendt sugere que, por meio de Robespierre, a compaixão teria adentrado a esfera política durante os eventos da Revolução Francesa, autores, como Chiba perceberam a acentuação desse fenômeno no pós-guerra. (CHIBA, 1995, p. 505-535). Em uma Europa arrasada pela Segunda Guerra - momento de descrença e decepção com as instituições políticas - o sentimento de compaixão pareceu ser uma saída para a preservação de valores do Ocidente europeu.

Nesse sentido, a Anistia Internacional, a exemplo do que ocorria no restante da Europa, teria recorrido à compaixão para pautar o seu trabalho de libertação dos “prisioneiros de consciência”. Ao longo do texto, procurou-se mostrar que esse sentimento esteve presente na linguagem e discursos utilizados nas cartas escritas para se dirigir a autoridades do governo britânico. Conforme foi exposto, o apelo à compaixão, entendido como sentimento capaz de ser direcionado apenas para o indivíduo, pareceu fundamental 
para a estratégia de ação da Anistia Internacional, cujo discurso almejava a transformação espiritual do ser humano.

Com a análise da documentação da Anistia Internacional, foi possível perceber como a organização lidou com o conflito entre o princípio de não-violência e a atenção dispensada a presos políticos que pertenceram a organizações armadas. Conforme foi visto, a Anistia buscou reafirmar que apenas poderiam ser considerados "prisioneiros de consciência" aqueles presos que não houvessem recorrido à violência. Ao mesmo tempo, o que se observou em relação ao caso do grupo Baader-Meinhof é que a organização, ao manifestar preocupação com condições carcerárias dos integrantes do grupo, defendeu que todo e qualquer preso, independente de ter recorrido à violência, teria direito a tratamento humano dentro das prisões.

Com esse artigo, buscou-se debater a adesão da Anistia Internacional ao princípio de não-violência. A posição da Anistia Internacional de defesa do tratamento humano a todos os presos independentemente do uso da violência como forma de luta política, sem dúvida, abriu precedentes para a defesa de presos políticos brasileiros do regime militar brasileiro. Tendo isso em vista, poderá se proceder à investigação de como a Anistia Internacional atuou em relação ao Brasil durante a Ditadura.

\section{Documentos consultados:}

Activities of Amnesty International in Brazil. Foreign Office Records. FCO 7/2205. National Archives, Londres.

Amnesty International's work on prison conditions of persons suspected or convicted of politically motivated crimes in the Federal Republic of Germany: Isolation and solitary confinement. London, England : Amnesty International, International Secretariat, 1980. Library of Congress, Washington. Amnesty International and the use of violence: An explanatory note. London: Amnesty International Publications, 1976. Library of Congress. Washington.

Prisoners of Conscience: an Amnesty International report. Amnesty International Publications, 1981. Library of Congress. Washington.

Informe da Divisão de Segurança e Informações do Ministério da Justiça. 19 de Julho de 1973. BR.AN, RIO.TT.O.MCP.AVU.250. Arquivo Nacional/ RJ.

Report on Allegations of Torture in Brazil. Relatório sobre as Acusações de Tortura. Anistia 
Internacional. 1972. 92 fls. 50-Z-30-4017. Fundo Deops/SP. Série dossiês. Arquivo Público do Estado de São Paulo (APESP).

\section{Bibliografia}

ARENDT, Hannah. On revolution. Londres: Penguin, 2006.

ARENDT, Hannah. Da revolução. São Paulo. Editora Ática, 1988

BUCHANAN, Tom. The truth will set you free: the making of amnesty international. Journal of Contemporary History. v.37, n.4, out., 2002, p.575-597. Disponível em: <www.jstor.org/stable/3180761>.

CANCELLI, Elizabeth. Testemunho e obliteração: da tragédia ao melodrama. Mimeo. 2011

CHIBA, Shin. Hannah Arendt on love and the political: Love, Friendship, and Citizenship. The Review of Politics. v.l. 57, n. 3, summer, 1995, p. 505-535. Published by: Cambridge University Press for the University of Notre Dame du lac on behalf of Review of Politics Disponível em: <http://www.jstor.org/stable/1408599>.

CRUZ, Fabio. Frente Brasileño de Informaciones e Campanha: os jornais de brasileiros exilados no Chile e na França (1968-1979) - Dissertação (Mestrado). Universidade de São Paulo, Faculdade de Filosofia, Letras e Ciências Humanas. Departamento de História. 2010.

CZAJKA, Rodrigo. A Revista Civilização Brasileira: projeto editorial e resistência cultural (1965-1968). Revista de Sociologia e Política. v.18, n. 35, p. 95-117. Fev. 2010. JUDT, Tony. Postwar: A history of Europe since 1945. Londres: Penguin, 2005.

LARSEN, Egon. A flame in Barbed Wire: the story of amnesty international. Nova York: WW Norton \& Company, 1979.

POWER, Jonathan. Like water on stone: the story of amnesty international. Londres: Penguin, 2002.

SAFATLE. Vladimir; TELES, Edson. (orgs.) O que resta da ditadura. São Paulo: Boitempo, 2010. 
Recebido em: 18/08/2013 Aprovado em: 16/10/2013 